\title{
Patents and small business risk: longitudinal evidence from the global financial crisis
}

\author{
Roberto Barontini and Jonathan Taglialatela \\ Institute of Management, Scuola Superiore Sant'Anna, Pisa, Italy
}

\begin{abstract}
Purpose - The purpose of this study is to shed light on the relationship between patent applications and longterm risk for small firms across the global financial crisis of 2008. During a crisis, firm risk often skyrockets, and small and medium enterprises face significant dangers to their business continuity. However, managers have a set of strategies that could be implemented to increase a firm's resilience, sustaining competitive advantages and improving access to financial resource. The authors focused on the investigating the impact of patenting activities on small business risk in a time of crisis.

Design/methodology/approach - This is a quantitative study based on a sample of Italian firms that applied for a patent in 2005. The changes in corporate credit ratings over a five-year period are related to different proxies of patent activity using multivariate regression analysis.

Findings - Firms that filed for a patent were more resilient, compared to the control sample, during the financial crisis. Innovative activities resulting in patent application seem to deliver strategic resources useful to tackle the crisis rather than increase riskiness. The moderating effect of patents on risk sensitivity is stronger for small firms and when the number of patents or the patent intensity is larger.

Originality/value - Limited evidence is available on how patent applications are related to risks for small firms during an economic crisis. The authors highlight that the innovative efforts resulting in patent applications can support small business resilience. The authors also point out that the implementation of patent information in small firms' credit score modeling is still an uncommon practice, while it is useful in estimating firm risk in a way more robust to exogenous credit shocks.
\end{abstract}

Keywords Global financial crisis, Patents, SMEs credit ratings, SMEs risk

Paper type Research paper

\section{Introduction}

The recent pandemic has highlighted the fragility of small and medium enterprises (SMEs) to the impact of macroeconomic shocks. During the global financial crisis (GCF), the level of uncertainty in the global credit markets rose steeply, and smaller firms struggled to acquire capital for both long-term investments and daily operations. Specifically, in 2009, around $20 \%$ of European SMEs were credit rationed, against an average rate of around $8 \%$ in "normal" business conditions, and their bankruptcy rates increased sharply. At the start of the pandemic, the frequency of capital rationing for SMEs peaked again at 17\% (European Central Bank, 2020), highlighting once more the imperative need to investigate risk factors and business strategies that can improve the likelihood of surviving crises.

A growing number of studies explore how small businesses and entrepreneurs deal with a crisis. The extant literature investigates the impact of macroeconomic shocks on startup creation (Davidsson and Gordon, 2016) and small firms' performance during a financial crisis

(C) Roberto Barontini and Jonathan Taglialatela. Published by Emerald Publishing Limited. This article is published under the Creative Commons Attribution (CC BY 4.0) licence. Anyone may reproduce, distribute, translate and create derivative works of this article (for both commercial and non-commercial purposes), subject to full attribution to the original publication and authors. The full terms of this licence may be seen at http://creativecommons.org/licences/by/4.0/legalcode

The authors thank the editor and the two anonymous reviewers for their constructive comments and insights.

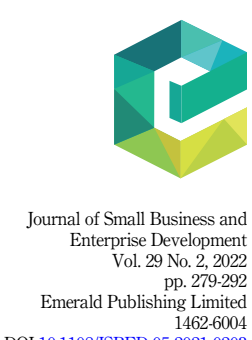

Received 26 May 2021

Revised 18 August 2021 Accepted 7 September 2021

Patents and small business risk 
JSBED

29,2

280
(Bartz and Winkler, 2016). Other studies identify entrepreneurial behaviors occurring within crises and disasters, isolating the characteristics of the best performers during and after a crisis (Cucculelli and Peruzzi, 2020; Devece et al., 2016; Gur et al., 2020). This paper contributes to this literature stream by adopting a different perspective, i.e. looking at firms that apply for a patent before the crisis and investigating the evolution of their business risk during the crisis. We focus on the following question, which to the best of our knowledge has been so far unexplored in the literature: do patenting efforts before a crisis contribute to increase firms' resilience to economic shocks? We believe that studying the GFC may provide useful insights into how SMEs deal with a crisis and improve our knowledge of the practices that increase their chances of survival during a crisis.

Small firms have different financing patterns to large firms and might suffer significantly from an exogenous credit supply shock (Berger and Black, 2011; Demirgüç-Kunt et al., 2020) that comes with a general increase in uncertainty and a general decline in creditworthiness (Bartz and Winkler, 2016; Lee et al., 2015).

In a crisis scenario, we argue that filing for a patent might affect the SME's risk, as reflected in its corporate credit ratings. On the one hand, filing for a patent represents the undertaking of a risky endeavor, which could contribute to further increase the fragility of SMEs in what is already a high-risk scenario. On the other hand, the beneficial effects of patenting might, to some extent, counteract the general increase in uncertainty (Czarnitzki and Toole, 2011) that accompanies a crisis, decreasing the cost of debt and improving a firm's chances of survival. The intangible assets and resources resulting from efforts in patenting might also generate a competitive advantage useful to tackle the crisis.

We empirically test these conjectures with a sample of 3,954 Italian firms that filed for a patent in 2005, using the evolution of their credit ratings as a proxy of their business risk. Results show that the credit ratings of SMEs who filed for a patent before the crisis worsened less than their peers during the crisis, exhibiting a lower increase in the probability of default. We also find a significant correlation between two proxies of "patent intensity" (the number of patent applications and the ratio of patents on sales) and changes in credit ratings - the more patents filed by a firm, the higher the resilience of the firm, measured by the lower increase in its default probability during the crisis. We also observe that this positive effect is not statistically different between the most active patentees and the remaining sample, contrasting the evidence of Czarnitzki and Kraft (2004), who find a positive impact on credit rating up to an optimum level of patenting effort after which rating improvement starts to decline.

Overall, the results show that applying for a patent is associated with a significant shield against macroeconomic shocks, and this information can be material for small firms' managers. Additionally, the implementation of patent information in SMEs default prediction models - a practice that is still uncommon (Ciampi et al., 2021) - can improve the ability of credit rating agencies to correctly estimate firm risk, increasing the efficacy in capital allocation and inducing small firms to perform innovative activities. Accordingly, policymakers could benefit as well from a better understanding of the links between patents and credit risk when designing the credit risk regulatory process and crisis policy.

This paper begins by discussing the theoretical background to this topic and highlighting the importance of investigating the relationship between patents and credit risk during a crisis. We then describe the data collection process and set out the empirical methodology. Finally, we discuss our findings and their implications.

\section{Theoretical background and hypotheses}

Corporate credit ratings are one of the main instruments used by lenders to decide whether or not a firm is worthy of credit and to evaluate the cost at which capital will be provided (Berger 
et al., 2011). The aim of credit ratings is to estimate how likely a firm is to fulfill its debt obligations according to its prospective cash flows.

We do acknowledge that several scholars have questioned the ability of rating agencies to focus on long-term perspectives and, therefore, adequately assess the probability of default consistent with these stated objectives (Altman and Rijken, 2004; Hovakimian et al., 2009). Even if these debates are beyond the scope of this paper, and we assume that credit ratings are reasonable indicators of a firm's riskiness, it is not obvious these ratings are based on the most appropriate information-both quantitative and qualitative - on a firm's future prospects. Drawing on a wider set of information than simple accounting data, the risk assessment could be more fitting, especially when estimating the riskiness over long time horizons and under increased uncertainty.

Although the literature has established a positive relationship between patents and credit ratings for large firms (Al-Najjar and Elgammal, 2013; Frey et al., 2020; Griffin et al., 2018; Hsu et al., 2015), the same correlations may not necessarily hold for smaller firms. SMEs are more likely than large firms to suffer from credit rationing due to higher levels of information asymmetry (Carpenter and Petersen, 2002; Gompers, 1999). Large firms must adopt accounting standards that are not usually mandatory for SMEs, resulting in less transparency for the latter. In addition, for SMEs, forward-looking information is rarely disclosed, and the attention of financial analysts and investors is much lower. All this information asymmetry forces lenders to demand a "lemon premium" (Akerlof, 1970) - that is, the additional cost on top of the cost of external debt to safeguard against the ignorance about firms' real prospects.

The GFC caused an impressive increase in global risk levels, which, in turn, increased the difficulty of accessing credit. Banks perceived SMEs as riskier (Piette and Zachary, 2015; Vermoesen et al., 2013), and this risk was reflected in poorer credit ratings and tighter credit conditions. A credit supply shock can exacerbate possible weaknesses in a firm's revenuegenerating processes, increasing both intrinsic and perceived risk levels. From a global perspective, credit ratings generally worsen overall, and the cost of debt capital increases.

How patents affect SMEs' risk and default probability could go either way. On the downside, filing for a patent implies that the firm undertakes innovation activities, which are intrinsically risky. The risky activity would be reflected in a downward change to the firm's default probability and credit ratings. Conversely, patent filings might be seen as the antecedent of profitable new products or processes and perhaps as reducing the long-term firm's risk exposure. According to this perspective, credit ratings should improve in comparison to firm competitors, alleviating the global impact of the crisis.

From a managerial perspective, the resource-based view (RBV) of the firm can provide a suitable framework to discuss the relationship between a patent application and risk. The RBV identifies the firm as the bundle of strategic resources, both tangible and intangible that the firm owns and controls. An essential characteristic of these resources is that they can provide a unique competitive advantage (Barney, 1991). Within the RBV framework, we argue that filing for a patent signals that a firm is gathering valuable strategic resources that could be precious in making the firm more resilient to negative scenarios.

An extension of the RBV that is focused on intangible assets - the knowledge-based view - also offers useful insights to describe how patents can signal differences in performance and perceived riskiness due to heterogeneity in firms' knowledge and capabilities (DeCarolis and Deeds, 1999). Filing for a patent is associated with a variety of activities that increase the accumulated knowledge stock and differentiates the firm from its competitors. In small businesses, where formal R\&D departments are generally nonexistent, other processes in the path leading to a patent application can significantly increase competences in an informal way, also through the interaction with external actors (including patent attorneys and technology experts). We argue that all these activities result in increased learning and
Patents and small business risk 
JSBED

29,2

organizational knowledge and contribute to the firm's competitive advantages. Previous studies described the possession of human, technological and social resources prior to an adverse event as a key factor (pro-active attribute) characterizing firm resilience and allowing it to withstand external shocks (Conz and Magnani, 2020). Accordingly, we argue that the competitive advantage and resources concealed by a patent application increase the resilience of the firm to the adverse effect of a crisis, shielding its riskiness from the generalized upward trend associated with exogenous macroeconomic shocks.

Existing empirical evidence shows that decisions to a patent by large firms are associated with lower corporate credit risk. Frey et al. (2020) find that a company's patent portfolio is positively related to its credit rating. Other authors focus on a firm's innovative efficiency, i.e. its patent output against its R\&D expenses, finding that this metric is positively correlated with the firm's credit ratings and bond pricing (Al-Najjar and Elgammal, 2013; Griffin et al., 2018; Hsu et al., 2015).

We came across three studies focused specifically on SMEs. Czarnitzki and Kraft (2004) analyze a sample of German SMEs to investigate how several indicators of innovative activity influence rating judgments. They find that patent stock has a significant positive impact on credit rating and identify an optimum level of innovation efforts, after which rating improvement starts to decline and even become negative due to an increased risk of failure of the activities attached.

Helmers and Rogers (2010) investigated bankruptcy determinants for a cohort of British firms, finding that firms with patents are less likely to exit the market. Pederzoli et al. (2013), meanwhile, analyzed the role of patent portfolios in SME credit risk modeling, finding that all other things being equal, the value of a firm's patent portfolio always reduces the probability of default (even if the size of the patent portfolio is not significant in reducing credit risk).

Summing up, past studies generally conclude that patents help to lower the probability of defaulting and lead to a better credit rating. However, none of these studies test their findings in a crisis setting, which is the focus of this article. We, therefore, aim to take this research stream further, analyzing how the relationship between patenting and credit risk is affected by a sudden increase in global riskiness. We also are interested in investigating whether the effect of patents on credit ratings across the crisis differs among SMEs and large firms. We posit that SMEs that filed for a patent before a crisis will benefit more - in comparison to their competitors - from the intangible resources connected to the patent filing, being, therefore, more resilient in coping with the crisis. Accordingly, our first hypothesis is

H1. Patenting before a crisis makes an SME more resilient to a general increase in riskiness.

In addition, we investigate whether the number of patents filed by an SME is a relevant determinant of changes in ratings during a crisis. As previously mentioned, Czarnitzki and Kraft (2004) found a positive effect determined by the patent intensity but also posited the existence of an optimum level of IP, suggesting that after a certain threshold, a firm's risk would increase, resulting in a lower credit rating. Therefore, we will test the following hypothesis:

H2a. SMEs that filed more patents are more resilient than non-patenting SMEs when coping with a generalized increase in riskiness.

$H 2 b$. There is an optimum level of patent-filing intensity, after which additional patenting efforts stop contributing to the SME's resilience in a time of crisis.

The next section describes our data and the methods we used to test our hypotheses. 


\section{Data and methods}

To build the dataset, we started with all Italian companies that filed for a patent at the European Patent Office in 2005. The Italian case is particularly relevant since, in Italy, the proportion of rationed SMEs, as opposed to those who asked for new credit, is much higher than in other EU countries (European Central Bank, 2014). Specifically, Italy's rationed small firms near 30\%, compared to $22 \%$ in Spain, $13 \%$ in France and 5\% in Germany, with the same share of firms asking for credit.

We excluded very large firms from the sample, i.e. firms with revenues higher than $€ 500$ million (3.1\% of the sample). We also excluded micro firms with revenues lower than $€ 1$ million (10.4\% of the sample) for two reasons. First, the dynamics of very small firms might relate poorly to the observed financial characteristics. Second, rating assessment by the rating agencies is rare for very small firms and could be associated with some selection criteria that might induce a bias in our results. We also excluded firms with missing values $(15.4 \%)$ to be left with 1,549 firms ( $71.1 \%$ of the original sample). Finally, from this sample of firms that applied for a patent, we select 439 firms across six industry sectors with the highest number of applicants (the industry sectors were determined from the three-digit ATECO codes in Amadeus).

The next step was to construct a control group that comprised all firms rated by Cerved of a similar size operating in these six sectors. The control group numbered 3,515 firms with some annual fluctuations as companies entered or exited the market or ceased to be rated by Cerved.

We then extracted financial data for these firms from the Amadeus database provided by Bureau van Dijk. Credit ratings for the period 2006-2010, along with information on the probability of default, were sourced from the Cerved Group, the most important rating agency in Italy. Cerved ratings are assigned on the basis of financials and several qualitative variables, like management quality, age of the firm, market position and payment behavior but do not take into account patent-related information (Cerved, 2011).

\section{Econometric results}

The empirical analysis starts with the examination of the characteristics of the firms included in the sample in the year 2005, the date of the patent application. Since our specific aim was to explore SMEs features, we divided the sample into three subsamples based on the size of revenues: small at revenues less than $€ 10$ million; medium at between $€ 10$ and 50 million and large at more than $€ 50$ million.

Table 1 shows that large and mid-sized firms constitute a larger share of the patentees' sample compared to the control sample, whereas the opposite happens for smaller firms. Further, the ratings distribution in Figure 1 suggests a strong relationship between the firm size and the rating assigned. From the graphs, it is evident that larger firms receive a significantly better evaluation both for patentees and for the control group. By contrast, ratings for the smaller firms are more dispersed and more frequently located in the mediumlow quality segments. This evidence is a first suggestion that in 2005 the risk assessment is different among different size classes and that a separate analysis might help to avoid possible bias due to the correlations between the patenting status and the firm size.

Table 2 shows the distribution of ratings for the patentees versus the control group in 2005. A chi-square test confirms a significant difference between the two, with patentees showing a higher proportion of firms within the better rating grades.

Further, Table 3 shows the same ratings comparison by company size. The significance tests indicate differences only for small-and medium-sized firms, supporting the idea that the positive correlation between patents and rating grades could be more important for firms of small and medium size.
Patents and small business risk 
JSBED

29,2

Table 1.

Composition of the sample by size and industry
Sample by firm size

Patentees

$(\%)$

Control sample

$(\%)$

\begin{tabular}{lrrrr}
\hline Small & 166 & 30.05 & 2,929 & 83.33 \\
Mid & 201 & 50.80 & 488 & 13.88 \\
Large & 72 & 19.15 & 98 & 2.79 \\
Total & 439 & 100 & 3,515 & 100 \\
\hline
\end{tabular}

Sample by industry classification (ATECO codes, \%)

\begin{tabular}{lcccccr} 
& $\begin{array}{c}\text { Patentees } \\
\text { Code }\end{array}$ & 24.4 (Pharma) & \multicolumn{2}{c}{$\begin{array}{c}\text { Control } \\
\text { 33.1 (Medical equip) }\end{array}$} & $\begin{array}{c}\text { Patentees } \\
25.2 \text { (Plastic packaging) }\end{array}$ \\
\hline Small & 20.00 & 43.62 & 47.83 & 83.98 & 32.98 & 80.30 \\
Mid & 53.33 & 31.54 & 47.82 & 12.14 & 50.00 & 17.27 \\
Large & 26.67 & 24.83 & 4.35 & 3.88 & 17.02 & 2.43 \\
Total & 100 & 100 & 100 & 100 & 100 & 100 \\
\hline
\end{tabular}

\begin{tabular}{|c|c|c|c|c|c|c|}
\hline \multirow{2}{*}{$\frac{\text { Code }}{\text { Small }}$} & \multicolumn{2}{|c|}{28.5 (Engineering) } & \multicolumn{2}{|c|}{$\begin{array}{l}29.2 \text { (Machinery - } \\
\text { general) }\end{array}$} & \multicolumn{2}{|c|}{$\begin{array}{l}29.5 \text { (Machinery - } \\
\text { excavation) }\end{array}$} \\
\hline & 40.63 & 87.53 & 40.50 & 78.63 & 40.29 & 85.71 \\
\hline Mid & 56.25 & 11.10 & 38.84 & 19.08 & 44.60 & 14.29 \\
\hline Large & 3.13 & 1.37 & 20.66 & 2.29 & 15.11 & 0.00 \\
\hline Total & 100 & 100 & 100 & 100 & 100 & 100 \\
\hline
\end{tabular}

Note(s): Firm size is defined by revenue: small $<€ 10$ million, medium $€ 10-50$ million, large $>€ 50$ million euros. The sectors are: 24.4 Manufacture of basic pharmaceutical products; 28.5 General mechanical engineering and metal treatment; 33.1 Manufacture of medical equipment for diagnosis, medical-surgical and veterinary material; 25.2 Manufacture of plastic packing goods; 29.2 Manufacture of machines of general use and other mechanical material; 29.5 Manufacture of machinery for mining, quarrying and construction

We also tested for differences between the two groups in the means of the default probabilities, debt ratios and profitability indexes in the year 2005. Space limitations prevent us from including the full results [1], but the summary finding is that the same pattern holds for the probability of defaults, i.e. there is a statistically significant difference between patentees and the control group across the full sample, but within each of the size brackets this result only holds for SMEs. Hence, small firms that filed for a patent in 2005 tend to receive better ratings than their non-patenting counterparts, which cannot be said for large firms. In the same vein, debt ratios turn out to be lower and profitability ratios higher in patenting firms.

These preliminary results show that SMEs that applied for a patent presents a lower default probability and better financial characteristics before the crisis, an outcome that can signal the competitive advantage against the control sample due to their innovative activity.

This evidence sparks interest in whether the evolution of credit ratings changed differently given the credit shocks of the GFC. As discussed in the hypothesis development, we expect that firms that filed for a patent will be more resilient in terms of risks relative to the general increase in risk crises induce. The counterfactual analysis in Figure 2 shows the changes in credit ratings over the period.

It is clear that SMEs suffered a worse decline in credit ratings than large firms but that the ratings of SMEs with patents decreased to a lesser extent than the control group.

In the next phase of the analysis, we conducted a series of OLS regressions with the aim to test more precisely the relationship among different firm characteristics and the change in 


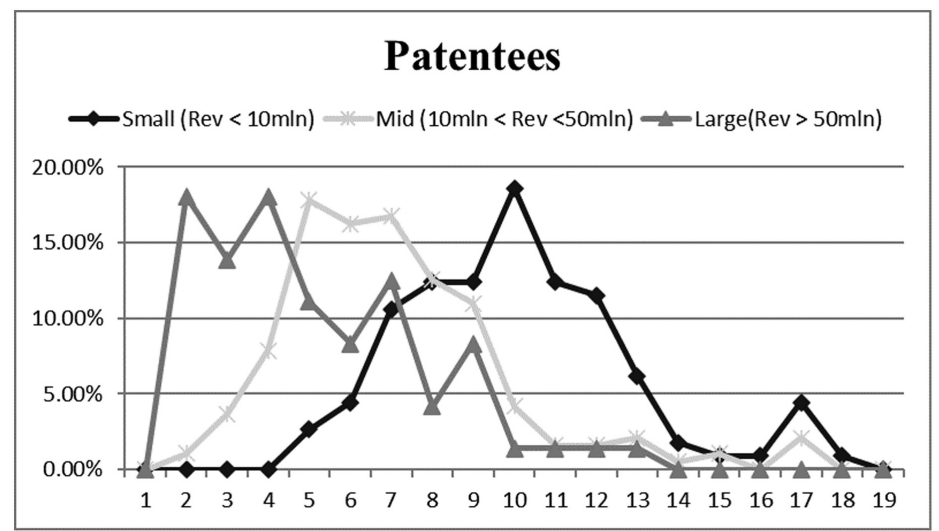

Patents and small business risk

285

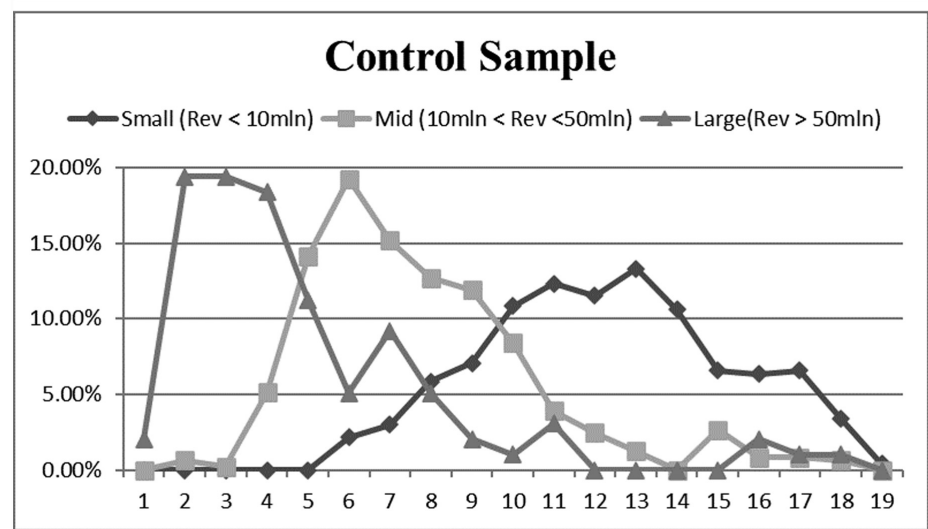

Note(s): Rating is on the horizontal axis, where 1 is the best rating and 19 is the worst. The percentage of firms having a specific type of rating is on the vertical axis

Figure 1. Rating frequency distribution by firm size (2006)

firm riskiness during the crisis. Table 4 lists the variables used, including the control dummies and dummies for fixed industry and geographic effects.

The first set of regressions, shown in Table 5, looked at the relationships between changes in the probability of default over the period and the potential contributors to those changes.

These results show that the firms that were more profitable prior to the GFC suffered less of a decrease in their financial performance during the GFC. The debt ratio coefficient indicates that high financial debt makes the firm less resilient to the crisis; quite surprisingly, it is significant only for medium and large firms. A possible reason for this may be that small firms often rely on the entrepreneur's personal assets as collateral to access finance, in which case, debt ratios are less of a factor for smaller firms. A firm's age tends to correlate to its market resilience (Sakai et al., 2010). Here, firm age was only significant for small firms, suggesting that once a firm reaches a certain size, its tenure is no longer relevant in driving the change in riskiness during the crisis.

Table 6 shows that added to the independent variables, the firms' credit ratings estimated prior to the GFC (probability of default in 2006) are strongly correlated to a future increase in riskiness. It is also worth pointing out that, with this variable added into the analysis, most of 
JSBED

29,2

\begin{tabular}{lccc}
\hline Rating & Patentees $(\%)$ & Control $(\%)$ & Total $(\%)$ \\
\hline 1 & 0.00 & 0.06 & 0.05 \\
2 & 3.99 & 0.63 & 0.95 \\
3 & 4.52 & 0.57 & 0.95 \\
4 & 7.45 & 1.22 & 1.82 \\
5 & 11.97 & 2.28 & 3.21 \\
6 & 11.17 & 4.61 & 5.24 \\
7 & 14.10 & 4.86 & 5.76 \\
8 & 10.90 & 6.77 & 7.17 \\
9 & 10.90 & 7.60 & 7.92 \\
10 & 7.98 & 10.21 & 10.00 \\
11 & 4.79 & 10.9 & 10.31 \\
12 & 4.52 & 9.96 & 9.43 \\
13 & 3.19 & 11.27 & 10.49 \\
14 & 0.80 & 5.85 & 8.07 \\
15 & 0.80 & 5.46 & 5.37 \\
16 & 0.27 & 5.63 & 4.96 \\
17 & 2.39 & 2.93 & 5.32 \\
18 & 0.27 & 0.34 & 2.67 \\
19 & 0.00 & 100.00 & 0.31 \\
Total & 100.00 & & 100.00 \\
Pearson Chi-square (19) $=483.5313-$ Pr $=0.000$ & & \\
\hline
\end{tabular}

Table 2.

Rating distributions

Pearson Chi-square $(19)=483.5313-\operatorname{Pr}=0.000$

Table 3.

Chi-square tests on the distribution of credit ratings between differently sized firms

\begin{tabular}{llr}
\hline Size & Pearson chi-square & $p$-value \\
\hline Small & Pearson chi-square $(15)=1.1 \mathrm{e}+03$ & 0.000 \\
Medium & Pearson chi-square $(17)=57.8173$ & 0.000 \\
Large & Pearson chi-square $(15)=13.1196$ & 0.593 \\
\hline
\end{tabular}

Figure 2.

The probability of default for patentees (Pat) and the control (Con)

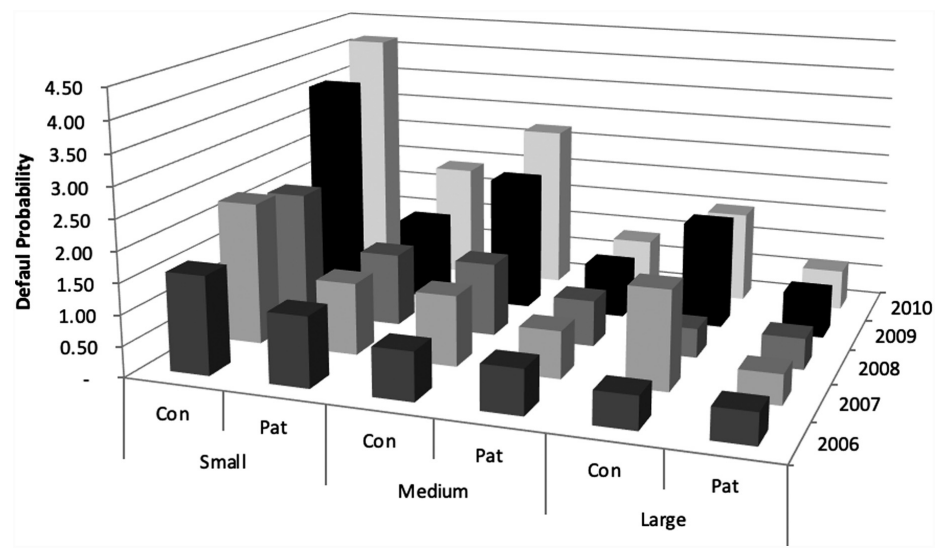

the other risk factors became insignificant. This result confirms the predictive power of credit ratings and their ability to summarize financial risk factors. 


\section{Variable}

RoI

RoE

Debt ratio

PD_2006

Patent

Age

Ln Pat

Ln Pat/Sal

Prolific patentee

Industry dummies

Geographic

dummies
Definition

EBIT/total assets

Net profit/equity

Total debt/total assets

Probability of default in 2006

Dummy $=1$ if the firm is included in the patenting sample

Natural logarithm of years since founded

$\log (1+$ number of patent filings)

$\log (1+$ number of patent filings/turnover $)$

Dummy $=1$ if the firms are in the top 25th percentile of the ratio "number of patent

filings/turnover"

The six ATECO industry codes

North, Center or South of Italy
Patents and small business risk

287

\begin{tabular}{|c|c|c|c|c|}
\hline & Small & Mid & Large & All \\
\hline Intercept & $16.130 * * *(3.941)$ & $10.099 * *(4.392)$ & 5.387 (5.832) & $14.019 * * *(2.775)$ \\
\hline ROI & $-0.154^{* * *}(0.049)$ & $-0.053^{* *}(0.024)$ & $-0.031(0.027)$ & $-0.078^{* * * *}(0.022)$ \\
\hline ROE & $-0.020^{* *}(0.010)$ & $-0.033^{*}(0.017)$ & $-0.010(0.023)$ & $-0.024^{* * * *}(0.007)$ \\
\hline Debt ratio & $0.000(0.001)$ & $0.139 * * *(0.044)$ & $0.264 * *(0.124)$ & $0.000(0.001)$ \\
\hline Age & $-5.712^{* * *}(0.969)$ & $0.080(0.978)$ & $0.269(1.21)$ & $-3.848 * * *(0.645)$ \\
\hline Industry & $\mathrm{Y}$ & $\mathrm{Y}$ & $\mathrm{Y}$ & $\mathrm{Y}$ \\
\hline Geography & $\mathrm{Y}$ & $\mathrm{Y}$ & $\mathrm{Y}$ & $\mathrm{Y}$ \\
\hline$N$ & 1,928 & 1,063 & 268 & 3,259 \\
\hline
\end{tabular}

Note(s): $* p<0.1,{ }^{* *} p<0.05, * * * p<0.01$; robust standard errors in parentheses

Table 4. Variables

Table 5.

Results of multivariate analysis on the determinants of the changes in credit ratings between 2006 and 2010

\begin{tabular}{lccrr}
\hline & Small & Mid & \multicolumn{1}{c}{ Large } & \multicolumn{1}{c}{ All } \\
\hline Intercept & $-8.154^{*}(4.492)$ & $-1.773(4.585)$ & $0.377(6.413)$ & $-6.722^{* * *}(3.074)$ \\
PDI_2006 & $9.425^{* * *}(0.901)$ & $9.790^{* * * *}(1.274)$ & $6.200^{* * *}(3.310)$ & $8.75^{* * * *}(0.618)$ \\
ROI & $-0.076(0.054)$ & $-0.047 *(0.024)$ & $-0.030(0.027)$ & $-0.046^{* * *}(0.022)$ \\
ROE & $-0.011(0.010)$ & $-0.003(0.018)$ & $-0.003(0.024)$ & $-0.012(0.012)$ \\
Debtratio & $-0.000(0.000)$ & $0.022(0.045)$ & $0.138(0.141)$ & $0.000(0.000)$ \\
Age & $-2.266^{* *}(1.002)$ & $1.050(0.972)$ & $1.098(1.295)$ & $-0.697(0.677)$ \\
Industry & $\mathrm{Y}$ & $\mathrm{Y}$ & $\mathrm{Y}$ & $\mathrm{Y}$ \\
Geography & $\mathrm{Y}$ & $\mathrm{Y}$ & $\mathrm{Y}$ & $\mathrm{Y}$ \\
$N$ & 1,905 & 1,050 & 267 & 3,222
\end{tabular}

Note(s): $* p<0.1,{ }^{* *} p<0.05,{ }^{* * *} p<0.01$; robust standard errors in parentheses

Our next set of regressions concerned changes in credit risk during the GFC for firms that applied for a patent, compared to the control group. Based on the previous tests, we only kept age and the 2006 default probability as controls for this analysis.

Table 7 shows that the credit ratings of firms with patents changed rather differently to those of the control group. Patent-filing firms experienced a lower impact from the general increase in risk associated with the GFC since the negative coefficient suggests that a firm's credit rating has decreased less than the average of the sample. Although patenting firms of all sizes saw a negative coefficient, only the results for the small- and medium-sized firms 
JSBED

29,2

\section{8}

Table 7.

Results of multivariate analysis on the determinants of the changes in credit ratings between 2006 and 2010 , including the patent interaction were statistically significant. Hence, patenting activity stood SMEs in better stead to weather the crisis, but the same cannot be said for large firms, leading us to accept H1.

To explore whether the number of a firm's patent applications is a significant factor in reducing corporate credit risk, we incorporated two proxies into the OLS regressions: the natural log of the number of patent filings (Model 1) and the variable "patent intensity," computed as the log of the number of patents divided by revenue, as a proxy of patenting efforts adjusted for firm size (Model 2). The results are given in Table 8.

Model 1 and 2 show us that both the number of patents a firm applies for and the patent intensity reduces the increase in risk through the crisis. This leads us to accept H2a.

Finally, to explore whether there is an optimum level of patenting activity, we defined a dummy variable called "Prolific Patentee" based on the ratio between the number of patent applications and revenues. The variable is a dummy equal to one if the firm is in the top 25th percentile of the index distribution and 0 otherwise. Table 9 shows that the two states of prolific patentees, when interacted with the default probability in 2006 , obtain coefficients very close in value and not statistically different. Thus, our results do not offer support for

\begin{tabular}{|c|c|c|c|c|}
\hline & Small & Mid & Large & All \\
\hline Intercept & $-10.810 * *(4.29)$ & $-4.866(4.518)$ & $-8.770(6.998)$ & -9.566 *** (3.014) \\
\hline PD_2006 & $10.529 * * *(0.771)$ & $13.088^{* * * *}(1.340)$ & $16.270 * * * *(2.041)$ & $10.154^{* * *}(0.575)$ \\
\hline Patent & $10.584 * *(4.447)$ & $6.108 * * *(2.229)$ & $3.813 * * *(2.861)$ & $5.965^{* * *}(1.786)$ \\
\hline PD_2006*Patent & $-10.432^{* * * *}(3.294)$ & $-10.175 * * *(2.506)$ & $-7.603(4.475)$ & $-7.560 * * *(1.728)$ \\
\hline $\mathrm{AGE}$ & $-1.894(0.990)$ & $1.192(0.959)$ & 2.432 (1.463) & $-0.347(0.677)$ \\
\hline Industry & Y & $\mathrm{Y}$ & $\mathrm{Y}$ & $\mathrm{Y}$ \\
\hline Geography & $\mathrm{Y}$ & $\mathrm{Y}$ & $\mathrm{Y}$ & $\mathrm{Y}$ \\
\hline$N$ & 1,954 & 1,053 & 272 & 3,279 \\
\hline
\end{tabular}

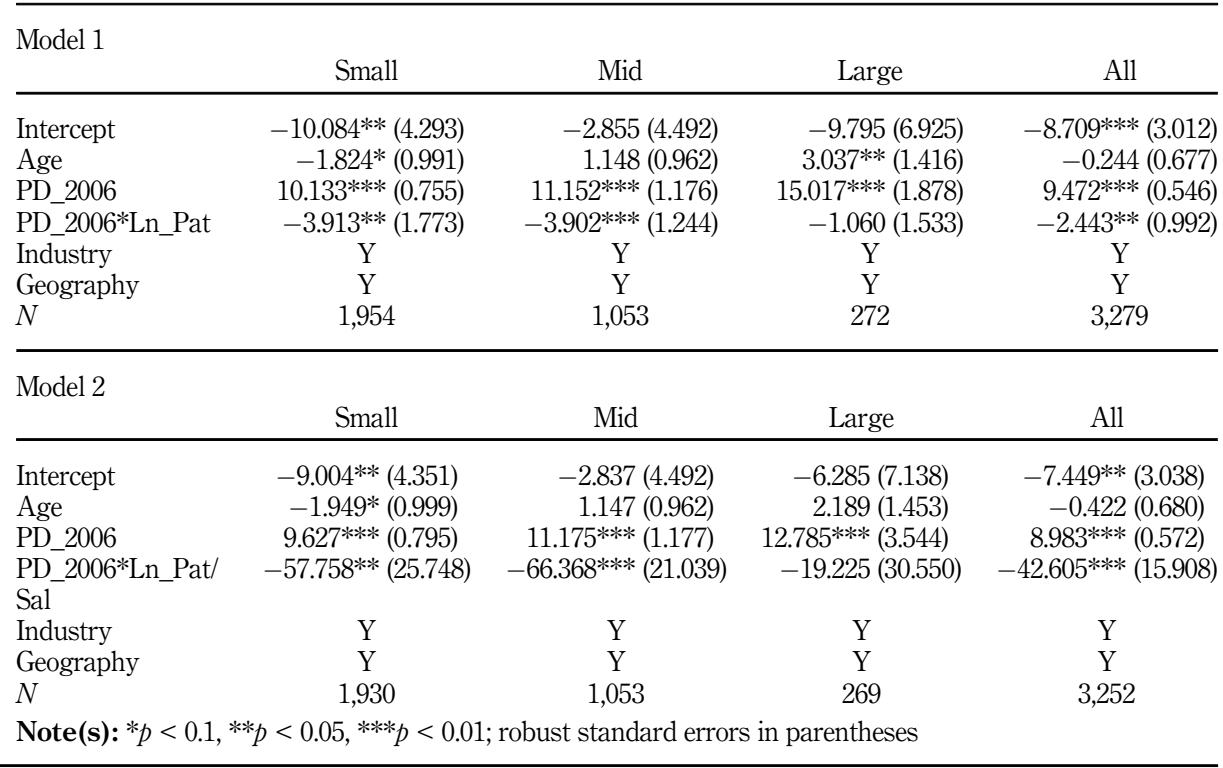

Table 8.

Results of multivariate analysis on the determinants of the changes in credit ratings between 2006 and 2010, including various specifications for patent intensity 
H2b since "Prolific Patentees" do not exhibit a risk dynamic significantly different for the remaining firms that applied for a patent.

\section{Conclusions}

COVID-19 crisis highlighted once again the fragility of SMEs and the importance of the development of strategies and behaviors able to increase their resilience. This paper focuses on the relationship between patents and risks for SMEs during a global crisis, an issue previously neglected in the literature.

Prior studies have established a negative relationship between patents and credit risks in large firms. Czarnitzki and Kraft (2004) provide evidence of a positive relationship between small firms with patents and the quality of their corporate credit ratings, while Pederzoli et al. (2013) show that a firm's patent portfolio always reduces the likelihood of default. However, none of these studies have investigated how the relationship between patents filings and credit risk evolves in times of crisis. We fill this gap in the literature, showing that SMEs suffer different consequences from an exogenous credit supply shock (Beck et al., 2008) and that patenting activity helps to soften those shocks. Hence, we find that given a generalized increase in riskiness caused by an exogenous shock such as the GFC, SMEs that filed for a patent will be rated with a lower credit risk than similar SMEs that did not file for a patent application.

Our results indicate that, unlike for larger firms, the ratings of SMEs that filed for a patent before the GFC were better able to cope with a generally tighter credit supply in the years after filing, compared to a control sample. These results show that filing for a patent is associated with better resilience to an exogenous credit supply shock, suggesting that the link between patents and uncertainty reduction found by previous literature (Czarnitzki and Toole, 2011) is relevant not only for granted patents but also at the patent application level. Complementary analyses show that when using the number of a firm's patent applications adjusted for firm size as a determinant of the change in riskiness, only smaller firms saw their defaultrisk "protected" by the crisis shock. Therefore, these results suggest that filing for a patent - and the consequent accumulation of intangible assets and resources - can provide small firms with improved resilience to face crises, while the effect is less significant for larger firms.

In their cross-section analysis of a sample of German firms, Czarnitzki and Kraft (2004) find some evidence that there is an optimum level of patents beyond which patenting stops lowering a firm's credit risk. However, our results show that the effect of risk reduction does not significantly change between "top patentees" and the other firms that file for a patent. Therefore, in our sample, the components of profitability and prospective cash flows that are positively linked to patent filing might be more relevant than the increase in risk implied by

\begin{tabular}{lcrrr}
\hline & \multicolumn{1}{c}{ Small } & \multicolumn{1}{c}{ Mid } & \multicolumn{1}{c}{ Large } & \multicolumn{1}{c}{ All } \\
\hline Intercept & $-9.060^{* *}(4.353)$ & $-3.120(4.503)$ & $-5.961(7.127)$ & $-7.521^{* *}(3.039)$ \\
Age & $-1.921^{*}(0.999)$ & $1.190(0.963)$ & $2.260(1.471)$ & $-0.419^{*}(0.680)$ \\
PD_2006 & $9.632 * * *(0.796)$ & $11.427^{* * *}(1.203)$ & $14.713^{* * *}(4.020)$ & $9.040^{* * *}(0.573)$ \\
PD_2006*Prolific patentee & $-3.612^{* *}(1.835)$ & $-4.453^{* * *}(1.569)$ & $-3.0394(3.954)$ & $-2.902^{* *}(1.188)$ \\
(lowest 75th percentile) & & & & \\
PD_2006*Prolific patentee & $-3.638(2.981)$ & $-5.315^{* *}(2.453)$ & $-7.762(4.934)$ & $-3.626^{*}(1.910)$ \\
(top 25 percentile) & 1,930 & 1,053 & 269 & 3,252 \\
$N$ & & &
\end{tabular}

Note(s): $* p<0.1,{ }^{* *} p<0.05, * * * p<0.01$; robust standard errors in parentheses
Patents and small business risk

289

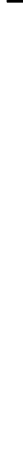


JSBED

29,2

pursuing risky R\&D endeavors, contrasting the results obtained by the authors. The difference between the two studies might be explained by the specificities of each sample analyzed; our dataset allows to investigate the rating evolution of the same firms during the entire timespan, whereas Czarnitzki and Kraft results are based on a sample where $57 \%$ of firms are observed only once in the sample (Czarnitzki and Kraft, 2004, p. 379). Accordingly, we might capture a relationship that extends further in time and is not immediately reflected in risk estimations. In addition, our results might be showing a dynamic that is characteristic of the time of crisis, i.e. efforts in accumulating additional intangible resources may be particularly valuable in contributing to firms' resilience during a generalized increase in riskiness.

Our findings have some important practical implications for SMEs, rating agencies and policymakers. Our results suggest that SMEs, which often suffer the harshest consequences of credit rationing following a crisis, might benefit from the efforts towards patent filings. This empirical evidence should induce the managers of SMEs to invest more in intangible resources that determine the decision to file for a patent since their default probability could suffer less from the generalized increase in riskiness.

Credit rating agencies could also benefit from the inclusion of data on patent applications in their risk assessment procedures. Since also trough global crisis patents are associated with higher resilience, rating agencies should include this information in their rating methodologies, particularly in the perspective of risk estimation in the long run.

From a policy perspective, since patents filings are a relevant determinant of a firm's risk over the medium-term, we call for the implementation of patent information in the coming policy initiatives on rating evaluations made by regulatory authorities.

These bottom-line conclusions lead us to the limitations of our study. We cannot claim a causal relationship between patenting and firms' risks because we cannot rule out the existence of unobservable variables that influence the relationship explored and that we cannot control for. However, we try to control for reverse causality using a control sample and including the pre-crisis default probability in regressions, and we are confident that the results provided are robust.

This study is the first evidence on the importance of patent applications in determining small firms' credit risks. Hopefully, it draws the attention of the research community to the important issue of how patents and other innovation protection methods affect SMEs' credit risks during a crisis. Future research might extend our results by providing evidence on different countries and including additional proxies of the accumulation of intangibles resources that could increase the resilience of the small firms during a global crisis.

\section{Note}

1. Readers wishing to see the full results tables should contact the corresponding author.

\section{References}

Akerlof, G.a. (1970), "The market for 'lemons': quality uncertainty and the market mechanism”, The Quarterly Journal of Economics, Vol. 84 No. 3, p. 488.

Al-Najjar, B. and Elgammal, M.M. (2013), "Innovation and credit ratings, does it matter? UK evidence", Applied Economics Letters, Vol. 20, pp. 428-431.

Altman, E.I. and Rijken, H.A. (2004), "How rating agencies achieve rating stability", Journal of Banking and Finance, Vol. 28 No. 11, pp. 2679-2714.

Barney, J. (1991), "Firm resources and sustained competitive advantage", Journal of Management, Vol. 17 No. 1, pp. 99-120. 
Bartz, W. and Winkler, A. (2016), "Flexible or fragile? The growth performance of small and young businesses during the global financial crisis - evidence from Germany", Journal of Business Venturing, Elsevier, Vol. 31 No. 2, pp. 196-215.

Beck, T., Demirgüç-Kunt, A. and Maksimovic, V. (2008), "Financing patterns around the world: are small firms different?”, Journal of Financial Economics, Vol. 89 No. 3, pp. 467-487.

Berger, A.N. and Black, L.K. (2011), "Bank size, lending technologies, and small business finance", Journal of Banking and Finance, Elsevier B.V., Vol. 35 No. 3, pp. 724-735.

Berger, A.N., Cowan, A.M. and Frame, W.S. (2011), "The surprising use of credit scoring in small business lending by community banks and the attendant effects on credit availability, risk, and profitability", Journal of Financial Services Research, Vol. 39 Nos 1-2, pp. 1-17.

Carpenter, R.E. and Petersen, B.C. (2002), "Is the growth of small firms constrained by internal finance?", Review of Economics and Statistics, Vol. 84 No. 2, pp. 298-309.

Cerved Group (2011), Rating Validation, Technical Document, Milan.

Ciampi, F., Giannozzi, A., Marzi, G. and Altman, E.I. (2021), "Rethinking SME default prediction: a systematic literature review and future perspectives", Scientometrics, Springer International Publishing, Vol. 126, doi: 10.1007/s11192-020-03856-0.

Conz, E. and Magnani, G. (2020), "A dynamic perspective on the resilience of firms: a systematic literature review and a framework for future research", European Management Journal, Elsevier, Vol. 38 No. 3, pp. 400-412.

Cucculelli, M. and Peruzzi, V. (2020), "Post-crisis firm survival, business model changes, and learning: evidence from the Italian manufacturing industry", Small Business Economics, Small Business Economics, Vol. 54 No. 2, pp. 459-474.

Czarnitzki, D. and Kraft, K. (2004), "Innovation indicators and corporate credit ratings: evidence from German firms", Economics Letters, Vol. 82, pp. 377-384.

Czarnitzki, D. and Toole, A.A. (2011), "Patent protection, market uncertainty, and R\&D investment", The Review of Economics and Statistics, Vol. 93 No. 1, pp. 147-159.

Davidsson, P. and Gordon, S.R. (2016), "Much ado about nothing? The surprising persistence of nascent entrepreneurs through macroeconomic crisis", Entrepreneurship: Theory and Practice, Vol. 40 No. 4, pp. 915-941.

DeCarolis, D.M. and Deeds, D.L. (1999), "The impact of stocks and flows of organizational knowledge on firm performance: an empirical investigation of the biotechnology industry", Strategic Management Journal, Vol. 20 No. 10, pp. 953-968.

Demirgüç-Kunt, A., Martinez Peria, M.S. and Tressel, T. (2020), "The global financial crisis and the capital structure of firms: was the impact more severe among SMEs and non-listed firms?", Journal of Corporate Finance, Vol. 60, p. 101514.

Devece, C., Peris-Ortiz, M. and Rueda-Armengot, C. (2016), "Entrepreneurship during economic crisis: success factors and paths to failure", Journal of Business Research, Elsevier, Vol. 69 No. 11, pp. 5366-5370.

European Central Bank (2020), Economic Bulletin, No. 4, Frankfurt am Main.

European Central Bank (2014), Survey on the Access to Finance of Small and Medium-Sized Enterprises in the Euro Area, Frankfurt am Main.

Frey, C.B., Neuhäusler, P. and Blind, K. (2020), "Patents and corporate credit risk", Industrial and Corporate Change, Vol. 29 No. 2, pp. 289-308.

Gompers, P.A. (1999), "Resource allocation, incentives and control: the importance of venture capital in financing entrepreneurial firms", in Acs, J.Z., Carlsson, B. and Karlsson, C. (Eds), Entrepreneurship, Small and Medium-Sized Enterprises and the Macroeconomy, Cambridge University Press, pp. 206-235.

Griffin, P.A., Hong, H.A. and Ryou, J.W. (2018), "Corporate innovative efficiency: evidence of effects on credit ratings", Journal of Corporate Finance, Elsevier B.V., Vol. 51, pp. 352-373. 
JSBED

29,2

292

Gur, F.A., Bendickson, J.S., Madden, L. and McDowell, W.C. (2020), "Entrepreneurial opportunity recognition in the face of disasters", International Journal of Entrepreneurial Behaviour and Research, Vol. 26 No. 4, pp. 671-693.

Helmers, C. and Rogers, M. (2010), "Innovation and the survival of new firms in the UK", Review of Industrial Organization, Vol. 36 No. 3, pp. 227-248.

Hovakimian, A., Kayhan, A. and Titman, S. (2009), "Credit ratings target”, Working paper, Baruch College and University of Texas, Austin, Unpublished.

Hsu, P.H., Lee, H.H., Liu, A.Z. and Zhang, Z. (2015), “Corporate innovation, default risk, and bond pricing”, Journal of Corporate Finance, Elsevier B.V., Vol. 35, May 2013, pp. 329-344.

Lee, N., Sameen, H. and Cowling, M. (2015), “Access to finance for innovative SMEs since the financial crisis”, Research Policy, Vol. 44 No. 2, pp. 370-380.

Pederzoli, C., Thoma, G. and Torricelli, C. (2013), "Modelling credit risk for innovative SMEs: the role of innovation measures", Journal of Financial Services Research, Vol. 44 No. 1, pp. 111-129.

Piette, C.H. and Zachary, M.D. (2015), "Sensitivity to the crisis of SME financing in Belgium", Economic Review, Vol. 3, pp. 31-45.

Sakai, K., Uesugi, I. and Watanabe, T. (2010), "Firm age and the evolution of borrowing costs: evidence from Japanese small firms", Journal of Banking and Finance, North-Holland, Vol. 34 No. 8, pp. 1970-1981.

Vermoesen, V., Deloof, M. and Laveren, E. (2013), "Long-term debt maturity and financing constraints of SMEs during the Global Financial Crisis", Small Business Economics, Vol. 41 No. 2, pp. $433-448$.

\section{Corresponding author}

Jonathan Taglialatela can be contacted at: jonathan.taglialatela@santannapisa.it

For instructions on how to order reprints of this article, please visit our website:

www.emeraldgrouppublishing.com/licensing/reprints.htm

Or contact us for further details: permissions@emeraldinsight.com 